\title{
Prolonged Release Mechanism of Action
}

National Cancer Institute

\section{Source}

National Cancer Institute. Prolonged Release Mechanism of Action. NCI Thesaurus. Code C149870.

Release of the substance(s) over a longer duration than would be achieved with a conventional-release product, achieved by a special formulation design and/or manufacturing method. 